\title{
Accreditation of (chemical) measurement laboratories is also about verifying the implementation of metrological principles in (chemical) measurement
}

\author{
Paul De Bièvre
}

Published online: 3 May 2009

(C) Springer-Verlag 2009

Accreditation, according to its self-declared principles is "a third party attestation related to a conformity assessment body conveying formal demonstration of its competence to carry out specific conformity assessment tasks" [1,2]. A previous definition described it-somewhat shorter and clearer-as "... formal recognition of competence to carry out specific tasks...".

It would appear logical that this should be done against (the latest) internationally agreed principles and concepts about 'measurement'.

After 10 years of difficult work on the 3 rd edition of the International Vocabulary of Metrology-basic and general concepts and associated terms (VIM) 3rd edition, JCGM 200:2008 ("VIM3"), we now have a set of such concepts since 2008-06-14 available for free from the publicly accessible website of the BIPM [3], the executive Bureau of the CGPM and CIPM, the world's top authorities in matters of measurement units. It is the best and uniquely consistent set of concepts governing 'measurement' i.e. 'metrology'. Patronizing the VIM, are BIPM (the International Bureau of Weights and Measures in Paris-Sèvres), IEC (the International Electrotechnical Commission), IFCC (the International Federation of Clinical Chemistry and Laboratory Medicine), ILAC (the International Laboratory Accreditation Cooperation), ISO (the International Organisation for Standardization), IUPAC (the International Union for Pure and Applied

P. De Bièvre $(\bowtie)$

Kasterlee, Belgium

e-mail: paul.de.bievre@skynet.be
Chemistry), IUPAP (the International Union for Pure and Applied Physics, OIML (the International Organisation for Legal Metrology).

It was voted into existence unanimously by these organisations through a formal international voting procedure (some of them even after a formal internal voting procedure such as is the case for ISO), after more than 700 comments had been received and been replied to. It would also follow that this stringent approval and voting mechanism, would give the Vocabulary the highest intercontinental, rather than just the international authority it needs-and deserves-. That entails that it would also offer the best guarantee for the fulfillment of the very useful target task formulated by ILAC: "Tested once, recognized and accepted everywhere" [4].

It would follow that the, so far best, internationally recognized principles for good measurement, leading to more 'competence in measurement' almost by definition, have been assembled and formulated in this "Vocabulary".

It would also follow naturally that being accredited, i.e. verified for achieved 'competence in measurement', is what measurement laboratories would be entitled to expect from accreditation.

One would expect that the acceptance and implementation of this consistent set of basic and general concepts as approved and unanimously agreed by a vote of a set of organizations which included ILAC, would be the subject of a public declaration of the accreditation bodies stating that "henceforth, accreditation bodies will take the VIM as one of the guides for their accreditation activity in measurement". Thus implementation of the principles and concepts of this guide would become common and intercontinentally applied, putting the conclusion of 'competence in measurement' on a common basis for all laboratories submitting to accreditation. 
Should we invite the international association of accreditation bodies to take a public stand on the use of the 2008 VIM in accreditation?

Or enter the Discussion Forum?

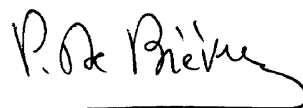

Paul De Bièvre

Editor-in-Chief

\section{References}

1. Unger P (2008) Comment on the Editorial "Does accreditation ensure competence in Measurement?". Accred Qual Assur 13:339. doi: 10.1007/s00769-008-0392-8

2. De Bièvre P (2008) Does accreditation ensure competence in measurement? Accred Qual Assur 13:1-2. doi:10.1007/s00769007-0346-6

3. VIM3 http://www.bipm.org/en/publications/guides/vim.html

4. Squirrell A (2008) Conformity assessment: providing confidence in testing and calibration. Accred Qual Assur 13:543-546. doi: 10.1007/s00769-008-0418-2 